Сравнительный анализ влияния пищевых добавок на технологию производства и качественные показатели хлеба пшеничного

\begin{tabular}{llll}
\hline \hline Мария А. Заикина & 1 & zaikina.marija@ya.ru & (1) 0000-0002-6457-6442 \\
Анна Е. Ковалева & 1 & a.e.kovaleva@ya.ru & (1) 0000-0001-7807-1755 \\
Эльвира А. Пьяникова & 1 & alia1969@ya.ru & (1) 0000-0003-4424-7323 \\
Анастасия С. Рязанцева & 1 & an.ryazantseva2016@ya.ru & \\
\hline
\end{tabular}

1 Юго-Западный государственный университет, ул. 50 лет Октября, 94, г. Курск, 305040, Россия

Аннотация. Одним из эффективных и экономически доступных способов обеспечения населения важными пищевыми веществами является обогащение продуктов массового потребления. Хлебобулочные изделия являются продуктами регулярного потребления в рационе питания. Комплексный подход в решении проблемы обеспечивается за счет исследований в области проектирования рецептурных составов и технологий новых видов хлебобулочных изделий, в том числе за счет применения нетрадиционного растительного сырья. Разработаны рецептуры и технология приготовления образцов пшеничного хлеба с яблочными выжимками с заменой части пшеничной муки на гречневую (первый образец хлеба) и рисовую муку (второй образец). Разработаны технологические параметры приготовления хлеба подового, безопарным способом. Исследовано влияние гречневой и рисовой муки на продолжительность технологического процесса приготовления хлеба; определено влияние вводимых пищевых добавок на органолептические и физико-химические показатели качества хлеба; показана сравнительная оценка содержания минеральных компонентов в разработанных и контрольном образцах. Применение вторичного яблочного сырья (свежемороженых яблочных выжимок), муки гречневой и рисовой в качестве нетрадиционных компонентов в технологии хлебобулочных изделий позволяет получить продукт с высокими органолептическими свойствами и богатым минеральным составом. Исследования влияния пищевых добавок на органолептические показатели хлебобулочного изделия позволяют сделать вывод о выраженном влиянии вносимых ингредиентов на внешний вид, цвет и состояние мякиша. Тем не менее, данные добавки не приводят к изменению вкуса и запаха выпеченных изделий. Анализ химического состава разработанных образцов хлеба пшеничного показал, что содержание железа и фосфора в них превышает значение контрольного образца в несколько раз.

Ключевые слова: хлеб пшеничный, гречневая мука, рисовая мука, яблочные выжимки, качественные показатели хлеба, сырьевой состав, анализ

\title{
Comparative analysis of the effect of food additives on the production technology and quality indicators of wheat bread
}

\begin{tabular}{llll}
\hline \hline Maria A. Zaikina & 1 & zaikina.marija@ya.ru & (D) 0000-0002-6457-6442 \\
Anna E. Kovaleva & 1 & a.e.kovaleva@ya.ru & (1) 0000-0001-7807-1755 \\
Elvira A. Pyanikova & 1 & alia1969@ya.ru & (1) 0000-0003-4424-7323 \\
Anastasia S. Ryazantseva $^{1}$ & an.ryazantseva2016@ya.ru & \\
\hline
\end{tabular}

1 South-West State University, 50 years of October Av., 94, Kursk, 305040, Russia

Abstract. One of the most effective and cost-effective ways to provide the population with important nutrients is the fortification of mass-consumption products. Bakery products are products of regular consumption in the diet. An integrated approach to solving the problem is provided through research in the design of prescription formulations and technologies of new types of bakery products, including through the use of non-traditional vegetable raw materials. Recipes and technology of preparation of samples of wheat bread with apple pomace replacing part of wheat flour with buckwheat (the first sample of bread) and rice flour (the second sample) are developed. The technological parameters of cooking hearth bread, in a non-paired way, have been developed. The influence of buckwheat and rice flour on the duration of the technological process of bread preparation is investigated; the influence of the introduced food additives on the organoleptic and physico-chemical indicators of bread quality is determined; a comparative assessment of the content of mineral compo-nents in the developed and control samples is shown. The use of secondary apple raw materials (fresh-frozen apple pomace), buckwheat and rice flour as non-traditional components in the technology of bakery products allows you to get a product with high organoleptic properties and a rich mineral composition. Studies of the effect of food additives on the organoleptic parameters of the bakery product allow us to make a conclusion about the pronounced effect of the added ingredients on the appearance, color and condition of the crumb. However, these additives do not lead to a change in the taste and smell of baked products. Analysis of the chemical composition of the developed samples of wheat bread showed that the content of iron and phosphorus in them exceeds the value of the control sample by many times.

Keywords: wheat bread, buckwheat flour, rice flour, apple pomace, bread quality indicators, raw material composition, analysis

\section{Введение}

Хлеб является основным продуктом питания для большинства групп населения. Хлеб, дополненный фенольными соединениями, привлекает все больше научных интересов

Для цитирования

Заикина М.А., Ковалева А.Е., Пьяникова Э.А., Рязанцева А.С. Сравнительный анализ влияния пищевых добавок на технологию производства и качественные показатели хлеба пшеничного // Вестник ВГУИТ. 2021. Т. 83. № 2. С. 79-86. doi:10.20914/23101202-2021-2-79-86

(C) 2021, Заикина М.А. и др. / Zaikina M.A. et al. в последние годы. Помимо улучшения антиоксидантов в хлебе, добавление фенольных соединений также влияет на физико-химические свойства и качества теста из-за различных взаимодействий с компонентами муки. Кроме того, фенольные соединения могут предотвращать For citation

Zaikina M.A., Kovaleva A.E., Pyanikova E.A., Ryazantseva A.S. Comparative analysis of the effect of food additives on the production technology and quality indicators of wheat bread. Vestnik VGUIT [Proceedings of VSUET]. 2021. vol. 83. no. 2. pp. 79-86. (in Russian). doi:10.20914/2310-1202-2021-2-79-86

This is an open access article distributed under the terms of the Creative Commons Attribution 4.0 International License 
образование канцерогенов, таких как акриламид, во время выпечки, тем самым функционируя в качестве антиканцерогенного агента в пищевых системах [1].

Важным источником пищевых волокон, пектина, водорастворимых витаминов, органических кислот, дубильных веществ, эфирных масел, флавоноидов и минеральных веществ [2-4] являются яблоки, занимающие более трети в обороте плодовой продукции. Яблоки, как ценный источник витамина С, обеспечивают до $15 \%$ физиологической потребности человека [5]. Применение продуктов переработки растительного сырья позволяет улучшать качество муки, осуществлять корректировку ее хлебопекарных свойств, а также усиливать функциональную направленность и пищевую ценность готовой продукции за счет добавлении фитопорошков из яблок или яблочных выжимок. Выжимки являются остаточным продуктом при производстве соков прямого отжима $[6,7]$, что позволяет обеспечивать безотходность производственного цикла. Фактор сезонности можно нивелировать за счет высушивания или замораживания ценного яблочного сырья, а также производства фитопорошков.

Яблочная выжимка является богатым источником углеводов, пектина, сырой клетчатки и минералов, и как таковой является хорошим источником питательных веществ [8]. Ценность пектина определяется возможностью комплексного воздействия на органы желудочнокишечного тракта, пищеварительной и кровеносной систем, выраженными регенерирующими, вяжущими и противовоспалительными свойствами. Важнейшим фактором для выбора источника пектиновых веществ является наличие сырьевых ресурсов. В местах произрастания яблок или их переработки целесообразно использовать яблочные выжимки.
Между тем, яблочные выжимки служат богатым источником биологически активных веществ - витаминов $\mathrm{C}, \mathrm{P}, \mathrm{E}, \beta$-каротина, тритерпеновых соединений, витаминов группы В, минеральных элементов (после отжатия сока в выжимках остается почти половина общего количества важнейших минеральных элементов), пищевых волокон, в том числе пектиновых веществ [9]. Пищевые волокна из разных источников используются для замены пшеничной муки при приготовлении хлебобулочных изделий.

Пищевые волокна оказывают большое влияние на технологию приготовления хлеба и его качественные показатели. Пищевые волокна могут улучшать текстуру, сенсорные характеристики и срок годности хлебобулочных изделий, благодаря их способности связывать воду и гелеобразующей способности [10-12].

Цель работы - проведение сравнительного анализа влияния гречневой и рисовой муки на технологию производства и качественные показатели хлеба пшеничного с яблочными выжимками.

\section{Материалы и методы}

Содержание всех компонентов в образцах хлеба с добавлением свежемороженых яблочных выжимок рисовой и гречневой муки определялось экспериментально. В ходе исследований при выпекании опытных партий образцов по органолептическим и физико-химическим показателям были установлены оптимальные соотношения компонентов, которые представлены в таблице 1 .

Для проведения эксперимента была взята рецептура, рассчитанная на основе унифицированной на хлеб пшеничный. Контрольным образцом служил хлеб из пшеничной муки, приготовленный по унифицированной рецептуре. Рецептуры хлеба представлены в таблице 1.

\section{Рецептуры хлеба}

Таблица 1 .

Bread recipe

\begin{tabular}{|c|c|c|c|}
\hline \multirow{2}{*}{$\begin{array}{c}\text { Сырьевой состав } \\
\text { Raw material composition }\end{array}$} & Образец & \multicolumn{2}{|c|}{ Sample } \\
\hline & \begin{tabular}{l|l} 
Контроль & Control \\
\end{tabular} & № 1 & № 2 \\
\hline $\begin{array}{c}\text { Мука пшеничная хлебопекарная высшего сорта, г } \\
\text { High-grade baking wheat flour, g }\end{array}$ & 160 & 140 & 140 \\
\hline Мука гречневая, г | Buckwheat flour, g & - & 20 & - \\
\hline \begin{tabular}{l|l} 
Мука рисовая, г & Riceflour, g
\end{tabular} & - & - & 20 \\
\hline Дрожжи прессованные, г | Pressed yeast, g & 5,5 & 5,5 & 5,5 \\
\hline \begin{tabular}{l|l} 
Вода питьевая, мл & Water, ml
\end{tabular} & 110 & 110 & 110 \\
\hline \begin{tabular}{l|l|l} 
Масло растительное, мл & Vegetable oil, ml \\
\end{tabular} & 10 & 10 & 10 \\
\hline Яблочные выжимки, г | Apple pomace, g & - & 30 & 30 \\
\hline \begin{tabular}{l|l} 
Соль поваренная, $\Gamma$ & Table salt, $g$ \\
\end{tabular} & 2,5 & 2,5 & 2,5 \\
\hline \begin{tabular}{l|l|l} 
Caxap, $г$ Sugar, g \\
\end{tabular} & 2,5 & - & - \\
\hline
\end{tabular}


При разработке рецептуры хлеба пшеничного с гречневой мукой и яблочными выжимками была использована стандартная технология производства безопарным способом, с некоторыми изменениями.

Выжимки из яблок предварительно размораживали и замачивали в смеси растительного масла и теплой воды (температура воды $28-30^{\circ} \mathrm{C}$ ). Смесь постоянно перемешивали до однородной консистенции. Затем она выстаивалась в течение 15-20 мин. - для хлеба с добавлением рисовой муки и 5-7 мин. - для хлеба с добавлением гречневой муки. Одновременно замешивались остальные ингредиенты (мука, соль, дрожжи). После этого смесь с выжимками добавлялась в тесто.

После замешивания тесто подвергалось брожению в течение 5-7 мин. При этом температура теста поднималась до $30^{\circ} \mathrm{C}$. Затем производилась обминка, после чего процесс брожения продолжался еще 5-7 мин.

Для повышения кислотности хлеба и сокращения процесса брожения в рецептуру введено яблочное сырье. Это позволило сократить процесс брожения. Затем разливали по формам. Хлеб для расстойки помещали на 20 мин в специальную камеру. Процесс расстойки осуществлялся при температуре $34-35^{\circ} \mathrm{C}$. В результате происходило увеличение теста в объеме. Выпекали хлеб при температуре 195-205 ${ }^{\circ} \mathrm{C}$. Длительность выпечки составляла 20 мин. Выпеченный хлеб постепенно охлаждали при комнатной температуре.

Для органолептической оценки была разработана шкала бальной оценки качества хлеба, в которой на каждый показатель отводилось максимальное количество баллов - 5 , общая сумма баллов составляла 40 баллов [14].

\section{Результаты и обсуждение}

Оценки качественных показателей выпеченных образцов хлеба проводилась с использованием экспертного и органолептического методов. Экспертный метод основан на том, что каждый из 5 экспертов, участвующих в опросе, присваивает каждому из критериев определенный балл.

На рисунке 1 представлены образцы хлеба с добавлением свежезамороженных яблочных выжимок, выпеченных по предложенным рецептурам, представленным в таблице 1 .

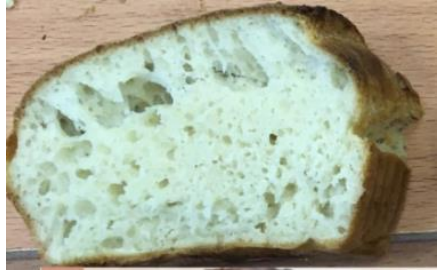

(a)

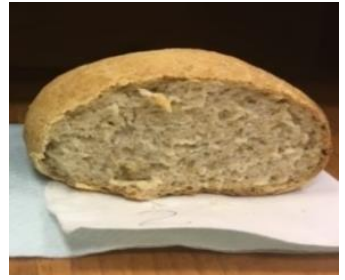

(b)

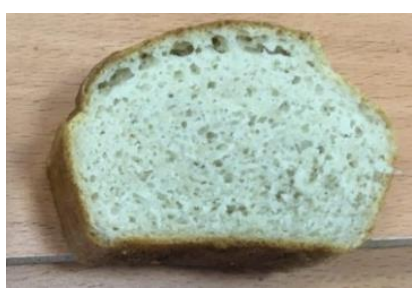

(c)

Рисунок 1. Внешней вид в разрезе выпеченных образцов хлеба: (а) контрольный образец, (b) с гречневой мукой, (c) с рисовой мукой

Figure 1. Appearance in the section of baked bread samples: (a) control sample, (b) with buckwheat flour, (c) with rice flour

Дегустаторы, используя свои органы чувств, провели оценку качества органолептических показателей разработанных образцов хлеба с использованием вторичного яблочного сырья и добавлением рисовой и гречневой муки.
Полученные результаты были обработаны и на основе их составлен протокол испытаний. Средние значения органолептических показателей качества образцов хлеба приведены в таблице 2.

Средние значения органолептических показателей качества образцов хлеба

Таблица 2 .

Table 2 .

Average values of organoleptic indicators of the quality of bread samples

\begin{tabular}{|c|c|c|c|c|c|c|c|c|c|}
\hline \multirow{2}{*}{$\begin{array}{c}\text { Образец } \\
\text { Samples }\end{array}$} & $\begin{array}{c}\text { Форма } \\
\text { Form }\end{array}$ & $\begin{array}{c}\text { Поверхность } \\
\text { Surface }\end{array}$ & $\begin{array}{c}\text { Цвет } \\
\text { Color }\end{array}$ & $\begin{array}{c}\text { Пропеченность } \\
\text { Bakedgoods }\end{array}$ & $\begin{array}{c}\text { Промес } \\
\text { Promes }\end{array}$ & $\begin{array}{c}\text { Пористость } \\
\text { Рorosity }\end{array}$ & $\begin{array}{c}\text { Вкус } \\
\text { Taste }\end{array}$ & $\begin{array}{c}\text { Запах } \\
\text { Smell }\end{array}$ & $\begin{array}{c}\text { Сумма баллов } \\
\text { Sum of points }\end{array}$ \\
\hline $\begin{array}{c}\text { Контроль } \\
\text { Control }\end{array}$ & 4,6 & 4,4 & 4,8 & 4,6 & 4,4 & 4,4 & 4,6 & 4,4 & 36,2 \\
\hline 1 & 4,6 & 4,8 & 4,6 & 5,0 & 5,0 & 4,6 & 4,8 & 4,8 & 38,2 \\
\hline 2 & 4,8 & 4,6 & 4,8 & 5,0 & 5,0 & 5,0 & 5,0 & 4,9 & 39,1 \\
\hline
\end{tabular}


Из данных таблицы 2 по результатам исследования органолептических показателей качества разработанных образцов хлеба видно, что они превосходят контрольный образец. Лучшим при этом оказался образец с добавлением рисовой муки, набравший 39,1 балла из 40 возможных. Образец хлеба с добавлением гречневой муки уступил ему 0,9 балла, набрав 38,2 баллов по всем показателям.

По показателю «форма» образец № 1 набрал 4,6 балла, образец № $2-4,8$ балла, что соответствует требованиям ГОСТ: форма округлая, не расплывчатая, без притисков.

Цвет у образца № 1 был светло-коричневый с равномерным распределением добавки из растительного сырья (он набрал 4,6 балла); у образца № 2 - светло-коричневый; мякиш белого цвета с легким сероватым оттенком.

По показателям «пропеченность» и «промес» оба образца получили по 5 баллов. Мякиш пропеченный, не влажный на ощупь; эластичный, после легкого надавливания пальцами принимал первоначальную форму. Комочков и следов непромеса в образцах не наблюдалось.

По показателю «пористость» образец № 1 набрал 4,6 балла: пористость развитая, без пустот и уплотнений, равномерная, но поры крупнее, чем у контрольного образца. У образца № 2

пористость развитая, без пустот и уплотнений, равномерная.

В образце хлеба № 1 вкус и запах получили по 4,8 балла: они были свойственными данному виду изделия, без постороннего привкуса и запаха. У образца № 2 вкус свойственный данному виду изделия, слегка сладковатый. По данному показателю образец набрал 5 баллов. Запах у данного образца набрал 4,9 балла: он свойственный внесенным вкусовым добавкам, без посторонних запахов.

Полученный готовый хлеб с дозировкой рисовой муки $12,5 \%$ имел хороший внешний вид (цвет мякиша), эластичность, поверхность без трещин и надрывов. При увеличении дозировки рисовой муки в рецептуре наблюдалось ухудшение показателей реологических свойств и эластичности хлеба.

Физико-химические показатели качества продукции характеризуют качество проведения технологических процессов [15-20], поэтому их определение является неотъемлемой частью оценки качества готовой продукции.

Для разработанных образцов хлеба была проведена физико-химическая оценка качества на соответствие ГОСТ 31805-2018. В результате проведения физико-химических испытаний для выпеченных образцов хлеба получили данные, представленные в таблице 3.

Таблица 3 .

Результаты проведения физико-химических испытаний для разработанных хлебов

Table 3.

Results of physical and chemical tests for the developed loaves

\begin{tabular}{|c|c|c|c|c|}
\hline \multirow[b]{2}{*}{$\begin{array}{l}\text { Показатель } \\
\text { Indicator }\end{array}$} & \multirow[b]{2}{*}{$\begin{array}{l}\text { ГОСТ } 31805-2018 \\
\text { GOST } 31805-2018\end{array}$} & \multicolumn{3}{|c|}{ Образец | Sample } \\
\hline & & $\begin{array}{c}\text { Контроль } \\
\text { Control }\end{array}$ & 1 & 2 \\
\hline \begin{tabular}{|l|l|} 
Влажность мякиша, \% & Humidity of the crumb, \%
\end{tabular} & $19-52$ & 25,57 & 25,98 & 43,6 \\
\hline Кислотность мякиша, ${ }^{\circ},<\mid$ Acidity of the crumb, ${ }^{\circ},<$ & 3,5 & 3,20 & 3,30 & 3,4 \\
\hline Пористость, \%, > | Porosity, \%, > & 68 & 69,25 & 73,30 & 73,3 \\
\hline
\end{tabular}

При сравнительном анализе полученных результатов исследуемых образцов по показателям влажность, кислотность и пористость все значения находятся в допустимых пределах и удовлетворяют требованиям. Но следует отметить, что при сравнении образца № 1 с образцом № 2 имеются значительные отклонения по влажности $25,98 \%$ и 43,6 \% соответственно. Это связано с тем, что рисовая мука не обладает влагоудерживающей способностью, что сказывается на влажности мякиша хлеба.
Хлеб с добавлением свежемороженных яблочных выжимок и заменой части пшеничной муки на рисовую или гречневую по органолептическим и физико-химическим показателям соответствовал показателям ГОСТ 31805-2018. И между собой образцы хлеба не имели значительных отличий.

Так как яблочное сырье богато железом, то с использованием спектрофотометра были проведены исследования на определение содержание данного нутриента в разработанных образцах хлеба (рисунки 2 и 3 ). 

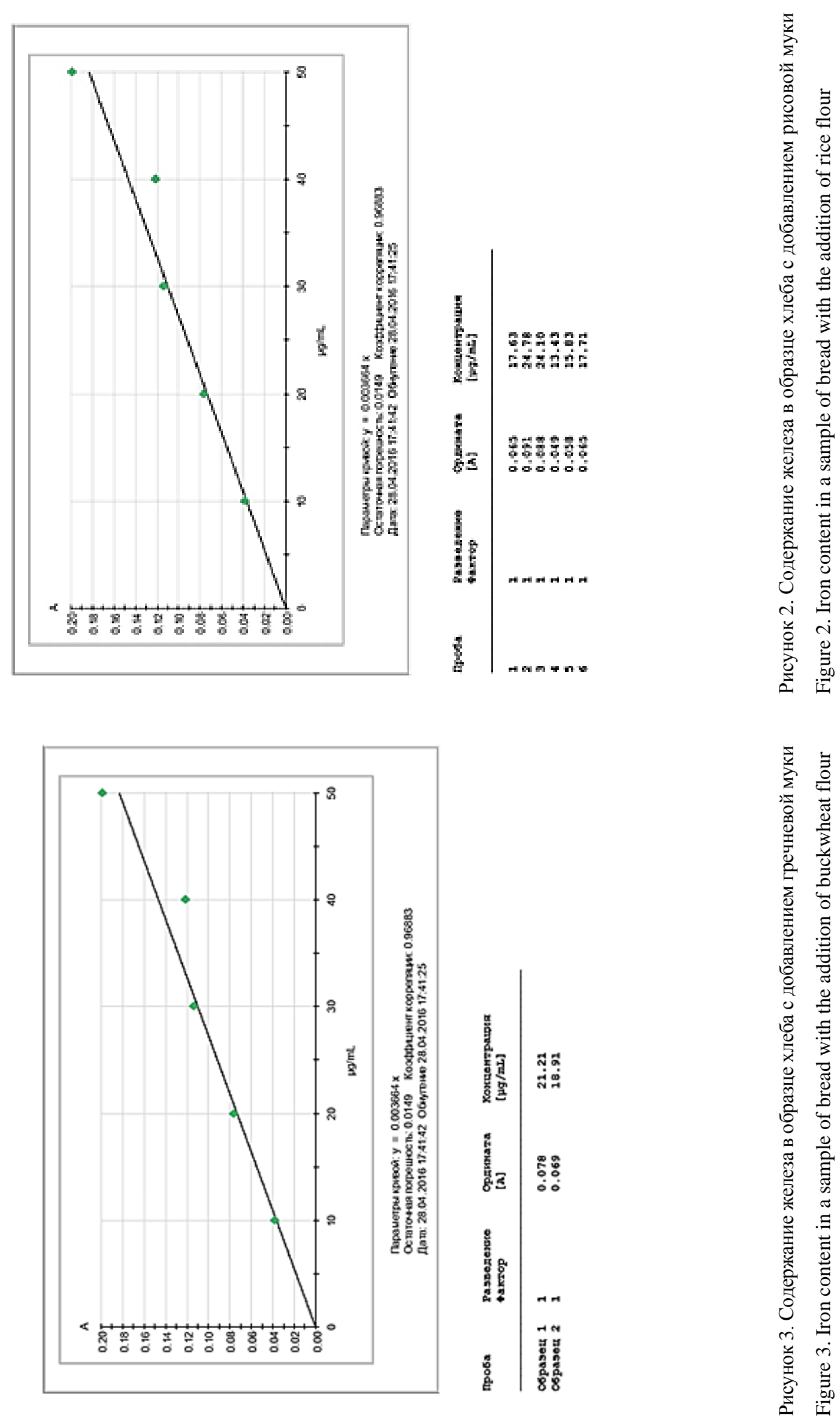
Согласно графиков рисунков 2 и 3 были получены средние значения содержания железа в образцах хлеба: в хлебе с добавлением рисовой муки - 18,9 мг/мл, в хлебе с добавлением гречневой муки - 20,06 мг/мл. Большая концентрация железа в образце хлеба с добавлением гречневой муки обусловлена тем, что гречневая мука в своем составе имеет также значительное содержание железа, по сравнению с рисовой мукой. Но, тем не менее, при сравнительном анализе образцов хлеба по всем исследованным показателям данная разница не так существенна.

\section{Заключение}

В ходе проведенного исследования по разработке рецептур хлебобулочных изделий с добавлением яблочного сырья и заменой части пшеничной муки рисовой и гречневой были сделаны следующие выводы:

- замачивание яблочных выжимок в растительном масле перед приготовлением теста позволяет получить хлеб с развитой пористостью и хорошим объемом. Потеря влаги происходит медленнее. Поэтому хлеб по истечении 72 часов остается свежим и не черствеет; post@vestnik-vsuet.ru

- продолжительность технологического процесса производства хлеба с добавлением рисовой муки увеличивается за счет увеличения продолжительности замачивания яблочных выжимок в растительном масле для лучшей связуюшей способности в последующем с рисовой мукой и уменьшения влажности теста;

- применение рисовой муки в количестве $12,5 \%$ способствует увеличению автолитической активности пшеничной муки. Для получения хлеба удовлетворительного качества с рисовой мукой необходимо использовать специальные подкисляющие природные добавки. В качестве подкисляющего компонента в рецептуре использовались свежемороженные яблочные выжимки;

- готовый хлеб с добавлением рисовой и гречневой муки имел хороший внешний вид (цвет мякиша), эластичность, поверхность без трещин и надрывов. По показателям «влажность», «кислотность» и «пористость» данные образцы удовлетворяют требованиям нормативной документации;

- предлагаемые рецептуры позволяют расширить ассортимент пшеничных хлебобулочных изделий.

\section{Литература}

1 Xu J., Wang W., Li Y. Dough properties, bread quality, and associated interactions with added phenolic compounds: A review // Journal of Functional Foods. 2019. V. 52. P. 629-639. doi: 10.1016/j.jff.2018.11.052

2 Скрипникова М.К., Скрипникова Е.В., Федулова Ю.А. Семечковые культуры средней полосы России доступный источник биологически активных веществ для обеспечения функционального питания школьников // Вопросы питания. 2014. Т. 83. № S3. С. 197-198.

3 Sardarodiyan M., Sani A.M. Natural antioxidants: sources, extraction and application in foods systems // Nutrition and Food Science. 2016. V. 46. № 3. P. 363-373. doi: 10.1108/NFS-01-2016-0005

4 Быкова Т.О., Макарова Н.В., Азаров О.И., Кузнецов А.А. Химический состав и показатели антиоксидантной активности сортовых яблок Самарской области // Известия высших учебных заведений. Пищевая технология. 2016. № 2-3. С. 21-24.

5 Тимакова Р.Т. Влияние ионизирующего излучения на изменение антиоксидантного потенциала свежих яблок // Проблемы развития АПК региона. 2019. № 3. С. 250-257.

6 Гайдукова О.П., Сокол Н.В., Чаусов В.М. Растительные сырьевые ресурсы для производства функциональных продуктов питания // Хлебобулочные, кондитерские и макаронные изделия XXI века: сб. тр. Краснодар: Изд-во Кубанского гос. техн. ун-та, 2009. С. 130-133.

7 Перфилова О.В. Яблочные выжимки как источник биологически активных веществ в технологии продуктов питания // Новые технологии. 2017. № 4. С. 65-71.

8 Shalini R., Gupta D.K. Utilization of pomace from apple processing industries: a review // Journal of Food Science and Technology. 2010. V. 47. P. 365-371. doi: 10.1007/s13197-010-0061-x

9 Chaldaev P.A., Svechnikov A.Y. The use of apple pomace for food production // Food industry. 2014. V. 4. P. 23-28.

10 Tsatsaragkou K., Protonotariou S., Mandala I. Structural role of fibre addition to increase knowledge of non-gluten bread // Journal of Cereal Science. 2016. V. 67. P. 58-67. doi: 10.1016/j.jcs.2015.10.003

11 Arslan M., Rakha A., Xiaobo Z., Mahmood M.A. Complimenting gluten free bakery products with dietary fiber: Opportunities and constraints // Trends in food science \& technology. 2019. V. 83. P. 194-202. doi: 10.1016/j.tifs.2018.11.011

12 Föste M., Verheyen C., Jekle M., Becker T. Fibres of milling and fruit processing by-products in gluten-free bread making: A review of hydration properties, dough formation and quality-improving strategies // Food chemistry. 2020. V. 306. P. 125451. doi: 10.1016/j.foodchem.2019.125451

13 Ковалева А.Е., Пьяникова Э.А., Ткачева Е.Д., Рязанцева А.С. Оценка показателей качества хлеба пшеничного, обогащенного вторичным яблочным сырьем // Вестник ВГУИТ. 2020. Т. 82. № 3. С. 200-206. doi: 10.20914/2310-1202-2020-3-200-206

14 Ковалева А.Е., Пьяникова Э.А., Ткачева Е.Д. Совершенствование рецептуры и технологии хлеба пшеничного с использованием яблочных выжимок // Вестник ВГУИТ. 2020. Т. 82. № 2. С. 61-66. doi: 10.20914/2310-1202-2020-2-61-66.

15 Науменко Н.В., Потороко И.Ю., Калинина И.В., Малинин А.В. и др. Совершенствование технологии производства хлебобулочных изделий, полученных с использованием ингредиентов растительного происхождения // Вестник ВГУИТ. 2019. Т. 81. № 2. С. 108-113. doi:10.20914/2310-1202-2019-2-108-113. 
16 Matos M.E., Rosell C.M. Quality indicators of rice-based gluten-free bread-like products: relationships between dough rheology and quality characteristics // Food and Bioprocess Technology. 2013. V. 6. №. 9. P. 2331-2341. doi: 10.1007/s11947-012-0903-9

17 Biletska Y., Djukareva G., Nekos A., Husliev A. et al. Investigation of Change of Quality Indicators of Gluten Free Bread During Storage // Eastern-European Journal of Enterprise Technologies. 2020. V. 5. №. 11. P. 107. doi: 10.15587/1729-4061.2020.215019

18 Biletska Y., Plotnikova R., Danko N., Bakirov M. et al. Substantiation of the expediency to use iodine-enriched soya flour in the production of bread for special dietary consumption // Eastern-European Journal of Enterprise Technologies. 2019. V. 5. №. 11. P. 48-55. doi: 10.15587/1729-4061.2019.179809

19 Morreale F., Garzón R., Rosell C.M. Understanding the role of hydrocolloids viscosity and hydration in developing gluten-free bread. A study with hydroxypropylmethylcellulose // Food Hydrocolloids. 2018. V. 77. P. 629-635. doi: 10.1016/j.foodhyd.2017.11.004

20 Dulova E.V., Kiseleva M.Y., Nasyrova Y.G., Kuzmina S. et al. Quality and consumer properties of bread baked from mixture of rye and wheat flour using iodine-containing additives // BIO Web of Conferences. EDP Sciences, 2020. V. 17. P. 00045. doi: 10.1051/bioconf/20201700045

\section{References}

1 Xu J., Wang W., Li Y. Dough properties, bread quality, and associated interactions with added phenolic compounds: A review. Journal of Functional Foods. 2019. vol. 52. pp. 629-639. doi: 10.1016/j.jff.2018.11.052

2 Skripnikova M.K., Skripnikova E.V., Fedulova Yu.A. Pome crops of central Russia - an affordable source of biologically active substances to provide functional nutrition for schoolchildren. Questions of nutrition. 2014. vol. 83. no. S3. pp. 197-198. (in Russian).

3 Sardarodiyan M., Sani A.M. Natural antioxidants: sources, extraction and application in foods systems. Nutrition and Food Science. 2016. vol. 46. no 3. pp. 363-373. doi: 10.1108/NFS-01-2016-0005

4 Bykova T.O., Makarova N.V., Azarov O.I., Kuznetsov A.A. Chemical composition and indicators of antioxidant activity of varietal apples of the Samara region. Proceedings of higher educational institutions. Food technology. 2016. no. 2-3. pp. 21-24. (in Russian).

5 Timakova R.T. The influence of ionizing radiation on the change in the antioxidant potential of fresh apples. Problems of the development of the agro-industrial complex of the region. 2019. no. 3. pp. 250-257. (in Russian).

6 Gaidukova O.P., Sokol N.V., Chausov V.M. Vegetable raw materials for the production of functional food products. Bakery, confectionery and pasta of the XXI century: collection of articles. tr. Krasnodar, Publishing house of the Kuban state. tech. University, 2009. pp. 130-133. (in Russian).

7 Perfilova O.V. Apple pomace as a source of biologically active substances in food technology. New technologies. 2017. no. 4. pp. 65-71. (in Russian).

8 Shalini R., Gupta D.K. Utilization of pomace from apple processing industries: a review. Journal of Food Science and Technology. 2010. vol. 47. pp. 365-371. doi: 10.1007/s13197-010-0061-x

9 Chaldaev P.A., Svechnikov A.Y. The use of apple pomace for food production. Food industry. 2014. vol. 4. pp. 23-28.

10 Tsatsaragkou K., Protonotariou S., Mandala I. Structural role of fibre addition to increase knowledge of non-gluten bread. Journal of Cereal Science. 2016. vol. 67. pp. 58-67. doi: 10.1016/j.jcs.2015.10.003

11 Arslan M., Rakha A., Xiaobo Z., Mahmood M.A. Complimenting gluten free bakery products with dietary fiber: Opportunities and constraints. Trends in food science \& technology. 2019. vol. 83. pp. 194-202. doi: 10.1016/j.tifs.2018.11.011

12 Föste M., Verheyen C., Jekle M., Becker T. Fibres of milling and fruit processing by-products in gluten-free bread making: A review of hydration properties, dough formation and quality-improving strategies. Food chemistry. 2020. vol. 306. pp. 125451. doi: 10.1016/j.foodchem.2019.125451

13 Kovaleva A.E., Pyanikova E.A., Tkacheva E.D., Ryazantseva A.S. Assessment of quality indicators of wheat bread, enriched with secondary apple raw materials. Proceedings of VSUET. 2020. vol. 82. no. 3. pp. 200-206. doi: 10.20914/23101202-2020-3-200-206 (in Russian).

14 Kovaleva A.E., Pyanikova E.A., Tkacheva E.D. Improving the recipe and technology of wheat bread using apple pomace. Proceedings of VSUET. 2020. vol. 82. no. 2. pp. 61-66. doi: 10.20914 / 2310-1202-2020-2-61-66 (in Russian).

15 Naumenko N.V., Potoroko I.Yu., Kalinina I.V., Malinin A.V. et al. Improving the technology of production of bakery products obtained with the use of ingredients of vegetable origin. Proceedings of VSUET. 2019. vol. 81. no. 2. pp. 108-113. doi: 10.20914 / 2310-1202-2019-2-108-113 (in Russian).

16 Matos M.E., Rosell C.M. Quality indicators of rice-based gluten-free bread-like products: relationships between dough rheology and quality characteristics. Food and Bioprocess Technology. 2013. vol. 6. no. 9. pp. 2331-2341. doi: 10.1007/s11947-012-0903-9

17 Biletska Y., Djukareva G., Nekos A., Husliev A. et al. Investigation of Change of Quality Indicators of Gluten Free Bread During Storag. Eastern-European Journal of Enterprise Technologies. 2020. vol. 5. no. 11. pp. 107. doi: 10.15587/1729-4061.2020.215019

18 Biletska Y., Plotnikova R., Danko N., Bakirov M. et al. Substantiation of the expediency to use iodine-enriched soya flour in the production of bread for special dietary consumption. Eastern-European Journal of Enterprise Technologies. 2019. vol. 5. no. 11. pp. 48-55. doi: 10.15587/1729-4061.2019.179809

19 Morreale F., Garzón R., Rosell C.M. Understanding the role of hydrocolloids viscosity and hydration in developing gluten-free bread. A study with hydroxypropylmethylcellulose. Food Hydrocolloids. 2018. vol. 77. pp. 629-635. doi: 10.1016/j.foodhyd.2017.11.004

20 Dulova E.V., Kiseleva M.Y., Nasyrova Y.G., Kuzmina S. et al. Quality and consumer properties of bread baked from mixture of rye and wheat flour using iodine-containing additives. BIO Web of Conferences. EDP Sciences, 2020. vol. 17. pp. 00045. doi: 10.1051/bioconf/20201700045 


\section{Сведения об авторах}

Мария А. Заикина к.т.н., доцент, кафедра товароведения, технологии и экспертизы товаров, Юго-Западный государственный университет, ул. 50 лет Октября, 94, г. Курск, 305040, Россия, zaikina.marija@ya.ru

(D)https://orcid.org/0000-0002-6457-6442

Анна Е. Ковалева к.х.н., доцент, кафедра товароведения, технологии и экспертизы товаров, Юго-Западный государственный университет, ул. 50 лет Октября, 94, г. Курск, 305040, Россия, a.e.kovaleva@ya.ru

Dhttps://orcid.org/0000-0001-7807-1755

Эльвира А. Пьяникова к.т.н., доцент, кафедра товароведения, технологии и экспертизы товаров, Юго-Западный государственный университет, ул. 50 лет Октября, 94, г. Курск, 305040, alia1969@ya.ru

Dhttps://orcid.org/0000-0003-4424-7323

Анастасия С. Рязанцева студент, кафедра товароведения, технологии и экспертизы товаров, Юго-Западный государственный университет, ул. 50 лет Октября, 94, г. Курск, 305040, an.ryazantseva2016@ya.ru

\section{Вклад авторов}

Все авторы в равной степени принимали участие в написании рукописи и несут ответственность за плагиат

\section{Конфликт интересов}

Авторы заявляют об отсутствии конфликта интересов.

\section{Information about authors}

Maria A. Zaikina Cand. Sci. (Engin.), associate professor, commodity science, technology and examination of goods department, South-West State University, 50 years of October Av., 94, Kursk, 305040, Russia, zaikina.marija@ya.ru

Dhttps://orcid.org/0000-0002-6457-6442

Anna E. Kovaleva Cand. Sci. (Chem.), associate professor, commodity science, technology and examination of goods department, South-West State University, 50 years of October Av., 94, Kursk, 305040, Russia, a.e.kovaleva@ya.ru Dhttps://orcid.org/0000-0001-7807-1755

Elvira A. Pyanikova Cand. Sci. (Engin.), associate professor, commodity science, technology and examination of goods department, South-West State University, 50 years of October Av., 94, Kursk, 305040, Russia, alia1969@ya.ru

Dhttps://orcid.org/0000-0003-4424-7323

Anastasia S. Ryazantseva student, commodity science, technology and examination of goods department, South-West State University, 50 years of October Av., 94, Kursk, 305040, Russia, an.ryazantseva2016@ya.ru

\section{Contribution}

All authors are equally involved in the writing of the manuscript and are responsible for plagiarism

\section{Conflict of interest}

The authors declare no conflict of interest.

$\begin{array}{lll}\text { Поступила 15/04/2021 } & \text { После редакции 13/05/2021 } & \text { Принята в печать 01/06/2021 }\end{array}$

$\begin{array}{lll}\text { Received 15/04/2021 } & \text { Accepted in revised 13/05/2021 } & \text { Accepted 01/06/2021 }\end{array}$ 